\title{
3 Research Square

\section{Alterations in Choroidal Volume and Determinants of Choroidal Volume and Visual Acuity in Entire Macula-involved Myopic Retinoschisis}

Shiwei Li

Shanghai Jiaotong University Affiliated Sixth People's Hospital

Tingting Li

Shanghai Jiaotong University Affiliated Sixth People's Hospital

Bin Lu

Shanghai Jiaotong University Affiliated Sixth People's Hospital

Yan Chen

Shanghai Jiaotong University Affiliated Sixth People's Hospital

Xueyan Zhang

Shanghai Jiaotong University Affiliated Sixth People's Hospital

Jianyan Hu

Shanghai Jiaotong University Affiliated Sixth People's Hospital

Qiang Wu ( $\nabla$ qiang.wu@shsmu.edu.cn )

Shanghai Jiaotong University Affiliated Sixth People's Hospital

\section{Research Article}

Keywords: choroidal volume, visual acuity, myopic rentinoschisis, optical coherence tomography

Posted Date: September 24th, 2021

DOl: https://doi.org/10.21203/rs.3.rs-753854/v1

License: (c) (i) This work is licensed under a Creative Commons Attribution 4.0 International License. Read Full License 


\section{Abstract \\ Background}

To evaluate alterations in the choroidal volume (CV) of eyes with entire macula-involved myopic retinoschisis (MRS) and to investigate predictive factors for $\mathrm{CV}$ and visual acuity.

\section{Methods}

This cross-sectional observational study recruited 32 MRS eyes, 52 non-MRS highly myopic eyes, and 55 emmetropic eyes. Retinal and choroidal morphological findings were obtained using SD-OCT. The CV of the three groups was compared, and factors associated with CV and BCVA were analyzed.

\section{Results}

The macular CV was significantly lower in MRS eyes than in emmetropic eyes $(P<0.0001)$ and in nonMRS highly myopic eyes $(P<0.05)$. The difference in $C V$ for MRS eyes among the superior $(0.34 \pm 0.16$ $\left.\mathrm{mm}^{3}\right)$, inferior $\left(0.33 \pm 0.17 \mathrm{~mm}^{3}\right)$, nasal $\left(0.27 \pm 0.12 \mathrm{~mm}^{3}\right)$ and temporal $\left(0.34 \pm 0.21 \mathrm{~mm}^{3}\right)$ quadrants was not significant $(P=0.3755)$. Multivariate regression analysis showed that the total macular $\mathrm{CV}$ in MRS eyes was negatively correlated with axial length $(P=0.0459)$, decreasing by $0.19 \mathrm{~mm}^{3}$ for each millimeter of axial length. Refractive error and defects in the ellipsoid zone (EZ) were associated with BCVA in logMAR units ( $P=0.0075$ and 0.0002 , respectively); BCVA decreased by 0.027 logMAR units for each diopter of myopia. The total macular retinal volume (RV) in MRS eyes with EZ defects was higher than that in eyes with intact or partially continuous EZs $(P=0.0460)$.

\section{Conclusion}

In MRS eyes, the choroid is thinner, the total macular CV deceases as the axial length increases, and the severity of myopia and the integrity of the $\mathrm{EZ}$, associated with the schisic extent are predictors of visual acuity, and the decrease of the macular $\mathrm{CV}$ is not the influencing factor of the visual function.

\section{Background}

The prevalence of high myopia is estimated to be as high as $4 \%$ worldwide and continues to increase ${ }^{[1-}$ 5]. The macular complications of high myopia are major causes of visual impairment ${ }^{[6-8]}$. Myopic retinoschisis (MRS) is a common pathological comorbidity of myopic traction maculopathy, and severe and progressive MRS can threaten visual function ${ }^{[9]}$. MRS is found in $6.5-31.3 \%$ of patients with high myopia according to different hospital-based and population-based studies ${ }^{[10,11]}$. Cross-sectional and retrospective studies have revealed that the opposing mechanical forces of eyeball expansion, uneven 
outward protrusions in posterior staphyloma and vitreoretinal attachments may promote the occurrence of MRS ${ }^{[12-15]}$. The cleavage of intraretinal tissue in the macula resulting from mechanical traction, retinal microstructural alterations such as disruption of the ellipsoid zone (EZ) and the presence of myopia-related macular degeneration in the retina can lead to varied degrees of visual loss in MRS, and MRS eyes with outer retinoschisis involving the entire macula have a much poorer visual prognosis ${ }^{[10,12,}$ 16]. It is generally considered that excessive stretching of the eyeball can damage the choroidal capillaries and further cause choroid thinning, which may lead to insufficient nutrition to the outer retina in high myopia ${ }^{[17,18]}$. Studies have reported that the choroid is thinner in highly myopic eyes than in normal emmetropic eyes and may be a predictor of poor visual acuity ${ }^{[19-21]}$, particularly in highly myopic eyes that have not yet progressed to the stage of pathological myopia ${ }^{[22]}$. However, the measurements of choroidal thickness at fixed points may not be useful for fully assessing the overall changes in the choroid due to unevenness of the choroidal thickness caused by the irregularity of the choroidal-scleral surface and the presence of posterior staphyloma ${ }^{[23,24]}$. Researchers have used the enhanced depth imaging (EDI) mode on spectral domain optical coherence tomography (SD-OCT) to measure choroidal volume (CV) to compensate for the shortcomings of these choroidal thickness measurements and have found that the CVs in eyes with myopic traction maculopathy are lower than those in highly myopic eyes

without choroidoretinal lesions ${ }^{[25]}$. However, these studies did not determine the variations in $\mathrm{CV}$ and the factors influencing CV in MRS eyes exclusively, especially in eyes with MRS involving the entire macula, which may represent a much severe status, or analyze the roles played by variations in CV and retinal morphological changes derived from mechanical traction on visual vision in these eyes.

Our study aimed to describe variations in CV in eyes with entire macula-involved MRS and to explore the predictive factors of $\mathrm{CV}$ and the associations of ocular characteristics with visual acuity.

\section{Methods}

\section{Patients}

This cross-sectional study recruited patients from the Department of Ophthalmology of the Sixth People's Hospital Affiliated with Shanghai Jiao Tong University from October 2019 to November 2020. We divided the patients into three groups: 1) patients with MRS involving the entire macular area (stage S4 as described by Shimada et al ${ }^{[14]}$ ) on SD-OCT; 2) highly myopic patients without MRS; and 3) normal emmetropic patients. Inclusion criteria for highly myopic eyes were an axial length $\geq 26 \mathrm{~mm}$ and a refractive error $\geq-6.00$ diopter $(D)$, and those for normal emmetropic patients were a refractive error from $-0.5 \mathrm{D}$ to $+0.5 \mathrm{D}$ and an axial length from $23.5 \mathrm{~mm}$ to $24.5 \mathrm{~mm}$. The exclusion criteria were 1) high myopia in which peripapillary diffuse choroidal atrophy was observed within a circular area $6 \mathrm{~mm}$ in diameter centered on the fovea; 2 ) retinal diseases such as full-thickness macular holes or choroidal neovascularization; 3) a history of vitreoretinal surgery, glaucoma or ocular trauma; 4) any systemic disease that could affect choroidal perfusion such as uncontrolled hypertension ${ }^{[25]}$ or diabetes; and 5) significant media opacity decreasing the quality of OCT imaging. The study complied with the tenets of 
the Helsinki Declaration and was approved by the Ethics Committee of Sixth People's Hospital Affiliated with Shanghai Jiao Tong University. The study was also registered in the Chinese clinical trial registry (http://www.chictr.org.cn/, registration number: ChiCTR2000038824). Written informed consent for participation was obtained from all patients.

\section{Clinical Examinations}

All patients were measured for refractive error and best corrected visual acuity (BCVA) in Snellen units by refractometer, noncontact intraocular pressure, and axial length by an IOL-Master (Carl Zeiss Meditec AC, Jena, Germany) and imaged for the presence of posterior staphyloma by B-scan ultrasonography, and posterior polar lesions by color fundus photography (Optos 200Tx scanning laser ophthalmoscope; Optos PLC, Dunfermline, United Kingdom). The Snellen units for BCVA were converted to logarithm of the minimal angle of resolution (logMAR) units for statistical analysis. The refractive error was calculated as the sum of the spherical power and half of the cylinder power. Myopic maculopathy was defined as the lack of myopic retinal degenerative lesions, a tessellated fundus, diffuse chorioretinal atrophy, patchy chorioretinal atrophy or macular atrophy according to the International Meta-Analysis for Pathologic Myopia (META-PM) classification system based on fundus photographs ${ }^{[26]}$. Diffuse chorioretinal atrophy was further classified into peripapillary diffuse choroidal atrophy and macular diffuse choroidal atrophy [22]. All patients underwent SD-OCT examination (Heidelberg Engineering, Heidelberg, Germany), consisting of horizontal and vertical A-scans with a length about $9.1 \mathrm{~mm}$ and a B-scan containing 31 scanning lines (covering a $30^{\circ} * 25^{\circ} /$ about $9.1 \mathrm{~mm} * 7.6 \mathrm{~mm}$ area) at an interval of $240 \mu \mathrm{m}$ through the center of the fovea in the horizontal direction. Before acquiring the image, we input the data of corneal curvature and axial length of highly myopic eyes in built-in software of SD-OCT in order to correct the error caused by the magnification effect. The Early Treatment Diabetic Retinopathy Study (ETDRS) grids were automatically generated by built-in Spectralis mapping software. In summary, the macula was divided into a central ring with a diameter of $1 \mathrm{~mm}$ centered on the fovea, an inner ring with a diameter between $1 \mathrm{~mm}$ and $3 \mathrm{~mm}$, and an outer ring with a diameter between $3 \mathrm{~mm}$ and $6 \mathrm{~mm}$; the three rings were then sectioned into superior, inferior, nasal and temporal quadrants, and the retinal volumes (RVs) in the entire macula and the 9 subfields were obtained, as the upper segmentation line lied in the internal limiting membrane, and the lower segmentation line was in line with the lower border of the retinal pigment epithelium (RPE)-Bruch's membrane complex. Examiners made manual adjustments when the segmentation lines did not correspond to the respective retinal tissue. Subsequently, the scanning mode was adjusted to EDI mode, and the same B-scan scanning method as above was applied. The segmentation line of the automatically marked internal limiting membrane was moved down to the layer of the RPE-Bruch's membrane complex, and the segmentation line of the automatically marked RPEBruch's membrane complex was moved down to the layer of the choroidoscleral boundary. Then, the software calculated the CVs in the nine subfields and the entire macula (Fig. 1). The CV was measured by two independent retina ophthalmologists. The MRS subgroup (outer schisis and inner schisis [occurring in the inner plexiform layer]), the integrity (intact, partially continuous, or defective) of the EZ, partial 
posterior vitreous detachment (PVD) and epimacular membrane were assessed based on SD-OCT. OCT examinations for all patients were performed from $10 \mathrm{am}$ to $3 \mathrm{pm}$ to reduce the influence of diurnal fluctuations ${ }^{[27]}$.

\section{Statistical Analysis}

Statistical analysis was performed using SAS software version 9.13 (SAS Institute Inc., Chicago, IL). Categorical variables were depicted as numbers, and continuous variables were depicted as the mean \pm standard deviation (SD). One-way analysis of variance and the Kruskal-Wallis test was used for comparing continuous variables among the three groups, and the independent $\mathrm{t}$-test was used for comparing continuous variables between the two groups. If the data did not conform to a normal distribution, the Kruskal-Wallis test and the Wilcoxon rank-sum test were performed. The chi-square test was used to compare the differences in categorical variables. Correlations between the different related

factors were analyzed by applying Spearman correlation analysis. Multivariate regression analysis was used to determine the factors influencing $\mathrm{CV}$ and BCVA. The intraclass correlation coefficient was adopted to test the interobserver agreement and reliability. $p<0.05$ was considered statistically significant.

\section{Results}

\section{Clinical Characteristics}

A total of 139 eyes from 139 patients were studied, including 32 MRS eyes, 52 non-MRS highly myopic eyes, and 55 normal emmetropic eyes. There were no significant differences among the three groups in terms of age, sex, or IOP ( $P=0.2621,0.8376$, and 0.4286 , respectively), and there were no significant differences in refractive error, axial length, or the presence of posterior staphyloma between the MRS group and the non-MRS group $(P=0.6850,0.6058$, and 0.3931 , respectively). The type of myopic maculopathy was distributed differently between the MRS group and the non-MRS group $(P=0.0183)$. MRS eyes had higher proportions of partial PVD and epimacular membrane than non-MRS highly myopic eyes ( $P=0.0361$ and 0.0389 , respectively). The BCVA in MRS eyes was worse than that in non-MRS eyes $(P<0.0001)$ (Table 1). In MRS group, 12 eyes had outer retinoschisis only, and 20 eyes had both outer and inner retinoschisis, the EZ was defective in 7 eyes and intact or partially continuous in 25 eyes. 
Table 1

Clinical Characteristics of the MRS, non-MRS High Myopia and Emmetropia Groups

\begin{tabular}{|c|c|c|c|c|c|c|c|}
\hline & $\begin{array}{l}\text { MRS } \\
(n= \\
32)\end{array}$ & $\begin{array}{l}\text { High } \\
\text { Myopia } \\
\text { without } \\
\text { MRS } \\
(n=52)\end{array}$ & $\begin{array}{l}\text { Emmetropia } \\
(n=55)\end{array}$ & $P$ & $P_{1}$ & $P_{2}$ & $P_{3}$ \\
\hline Age (years) & $\begin{array}{l}65.1 \\
\pm 9.58\end{array}$ & $64.7 \pm 9.78$ & $67.7 \pm 7.81$ & 0.2621 & 0.9323 & 0.1864 & 0.1095 \\
\hline Sex (n) F:M & $8 / 24$ & $16 / 36$ & $15 / 40$ & 0.8376 & 0.5698 & 0.8167 & 0.6903 \\
\hline $\begin{array}{l}\text { Refractive error } \\
(D \pm S D)\end{array}$ & $\begin{array}{l}-12.7 \\
\pm 5.33\end{array}$ & $\begin{array}{l}-12.0 \pm \\
3.72\end{array}$ & $0.30 \pm 0.77$ & $<.0001$ & 0.6850 & $<.0001$ & $<0.0001$ \\
\hline Axial length $(\mathrm{mm})$ & $\begin{array}{l}29.4 \\
\pm 1.53\end{array}$ & $29.0 \pm 1.41$ & $23.9 \pm 0.48$ & $<.0001$ & 0.6058 & $<.0001$ & $<.0001$ \\
\hline $\begin{array}{l}\text { Posterior } \\
\text { staphyloma(n) } \\
\text { (present/absent) }\end{array}$ & $26 / 6$ & $38 / 14$ & 0 & - & 0.3931 & - & - \\
\hline $\begin{array}{l}\text { Type of myopic } \\
\text { maculopathy }\end{array}$ & & & & - & 0.0183 & - & - \\
\hline $\begin{array}{l}\text { no myopic retinal } \\
\text { degenerative lesion }\end{array}$ & 0 & 0 & - & & & & \\
\hline tessellated fundus & 1 & 4 & - & & & & \\
\hline PDCA & 11 & 27 & - & & & & \\
\hline MDCA & 16 & 20 & - & & & & \\
\hline $\begin{array}{l}\text { patchy chorioretinal } \\
\text { atrophy }\end{array}$ & 4 & 1 & - & & & & \\
\hline macular atrophy & 0 & 0 & - & & & & \\
\hline $\begin{array}{l}\text { Partial PVD } \\
\text { (present/absent) }\end{array}$ & $7 / 25$ & $6 / 46$ & 0 & - & 0.0361 & - & - \\
\hline $\begin{array}{l}\text { epimacular } \\
\text { membrane } \\
\text { (present/absent) }\end{array}$ & $15 / 17$ & $13 / 39$ & 0 & - & 0.0389 & - & - \\
\hline IOP $(\mathrm{mmHg})$ & $\begin{array}{l}14.7 \\
\pm 2.15\end{array}$ & $14.5 \pm 1.92$ & $14.4 \pm 2.22$ & 0.4286 & 0.3940 & 0.4333 & 0.3051 \\
\hline
\end{tabular}

$D$ diopter; $S D$ standard deviation; $P D C A$ peripapillary diffuse choroidal atrophy; $M D C A$ macular diffuse choroidal atrophy; IOP intraocular pressure; LogMAR logarithm of the minimal angle of resolution 


\begin{tabular}{|c|c|c|c|c|c|c|c|}
\hline & $\begin{array}{l}\text { MRS } \\
(n= \\
32)\end{array}$ & $\begin{array}{l}\text { High } \\
\text { Myopia } \\
\text { without } \\
\text { MRS } \\
(n=52)\end{array}$ & $\begin{array}{l}\text { Emmetropia } \\
(n=55)\end{array}$ & $P$ & $P_{1}$ & $P_{2}$ & $P_{3}$ \\
\hline BCVA (logMAR) & $\begin{array}{l}0.50 \\
\pm 0.25\end{array}$ & $0.26 \pm 0.18$ & $0.08 \pm 0.10$ & $\stackrel{<}{0.0001}$ & $\begin{array}{l}< \\
0.0001\end{array}$ & $\begin{array}{l}< \\
0.0001\end{array}$ & $<.0001$ \\
\hline
\end{tabular}

\section{Choroidal Volume Of The Three Groups}

The intraclass correlation coefficients for the $\mathrm{CV}$ at all locations in the three groups ranged from 0.89 to 0.93. The CVs of the nine subfields and the entire macula in highly myopic eyes with and without MRS were significantly lower than those in emmetropic eyes (all $P<0.0001$ ). MRS eyes had significantly lower CVs than non-MRS highly myopic eyes in the ETDRS subfields and the entire macula (all $P<0.05$ ) (Table 2) (Fig. 2). Among MRS eyes, there was no significant difference in the $\mathrm{CV}$ among the superior $\left(0.34 \pm 0.16 \mathrm{~mm}^{3}\right)$, inferior $\left(0.33 \pm 0.17 \mathrm{~mm}^{3}\right)$, nasal $\left(0.27 \pm 0.12 \mathrm{~mm}^{3}\right)$ and temporal $\left(0.34 \pm 0.21 \mathrm{~mm}^{3}\right)$ quadrants $(P=0.3755)$. 
Table 2

Comparison of the Choroidal Volume $\left(\mathrm{mm}^{3}\right)$ of 9 Grids Among MRS, Non-MRS high myopia and Emmetropia groups

\begin{tabular}{|c|c|c|c|c|c|c|c|}
\hline & $\begin{array}{l}\text { MRS } \\
(n= \\
32)\end{array}$ & $\begin{array}{l}\text { non-MRS high } \\
\text { myopia } \\
(n=52)\end{array}$ & $\begin{array}{l}\text { Emmetropia } \\
(n=55)\end{array}$ & $P$ & $P_{1}$ & $P_{2}$ & $P_{3}$ \\
\hline Total $\left(\mathrm{mm}^{3}\right)$ & $\begin{array}{l}1.36 \pm \\
0.62\end{array}$ & $1.66 \pm 0.57$ & $5.37 \pm 1.45$ & $<.0001$ & 0.0083 & $<.0001$ & $\begin{array}{l}< \\
0.0001\end{array}$ \\
\hline $\begin{array}{l}\text { subfoveal } \\
\left(\mathrm{mm}^{3}\right)\end{array}$ & $\begin{array}{l}0.03 \pm \\
0.02\end{array}$ & $0.05 \pm 0.20$ & $0.16 \pm 0.05$ & $\hat{0} .0001$ & 0.0491 & $\hat{0} .0001$ & $\begin{array}{l}< \\
0.0001\end{array}$ \\
\hline $\begin{array}{l}\text { Inner superior } \\
\left(\mathrm{mm}^{3}\right)\end{array}$ & $\begin{array}{l}0.08 \pm \\
0.03\end{array}$ & $0.10 \pm 0.04$ & $0.33 \pm 0.10$ & $<.0001$ & 0.0117 & $<.0001$ & $<.0001$ \\
\hline $\begin{array}{l}\text { Outer superior } \\
\left(\mathrm{mm}^{3}\right)\end{array}$ & $\begin{array}{l}0.27 \pm \\
0.13\end{array}$ & $0.35 \pm 0.13$ & $1.10 \pm 0.26$ & $<.0001$ & 0.0039 & $<.0001$ & $<.0001$ \\
\hline $\begin{array}{l}\text { Inner inferior } \\
\left(\mathrm{mm}^{3}\right)\end{array}$ & $\begin{array}{l}0.07 \pm \\
0.03\end{array}$ & $0.09 \pm 0.03$ & $0.30 \pm 0.09$ & $<.0001$ & 0.0179 & $<.0001$ & $<.0001$ \\
\hline $\begin{array}{l}\text { Outer inferior } \\
\left(\mathrm{mm}^{3}\right)\end{array}$ & $\begin{array}{l}0.26 \pm \\
0.14\end{array}$ & $0.34 \pm 0.14$ & $0.98 \pm 0.32$ & $<.0001$ & 0.0080 & $<.0001$ & $<.0001$ \\
\hline $\begin{array}{l}\text { Inner nasal } \\
\left(\mathrm{mm}^{3}\right)\end{array}$ & $\begin{array}{l}0.06 \pm \\
0.03\end{array}$ & $0.08 \pm 0.04$ & $0.33 \pm 0.19$ & $<0.0001$ & 0.0149 & $<.0001$ & $\begin{array}{l}< \\
0.0001\end{array}$ \\
\hline $\begin{array}{l}\text { Outer } \\
\text { nasal }\left(\mathrm{mm}^{3}\right)\end{array}$ & $\begin{array}{l}0.21 \pm \\
0.09\end{array}$ & $0.25 \pm 0.08$ & $0.83 \pm 0.34$ & $\begin{array}{l}< \\
0.0001\end{array}$ & 0.0421 & $\begin{array}{l}< \\
0.000\end{array}$ & $\begin{array}{l}< \\
0.0001\end{array}$ \\
\hline $\begin{array}{l}\text { Inner temporal } \\
\left(\mathrm{mm}^{3}\right)\end{array}$ & $\begin{array}{l}0.07 \pm \\
0.04\end{array}$ & $0.09 \pm 0.04$ & $0.32 \pm 0.09$ & $\begin{array}{l}< \\
0.0001\end{array}$ & 0.0274 & $<0.0001$ & $<0.0001$ \\
\hline $\begin{array}{l}\text { Outer temporal } \\
\left(\mathrm{mm}^{3}\right)\end{array}$ & $\begin{array}{l}0.27 \pm \\
0.17\end{array}$ & $0.33 \pm 0.16$ & $1.05 \pm 0.28$ & $<.0001$ & 0.0170 & $<.0001$ & $<.0001$ \\
\hline
\end{tabular}

Factors Associated with the Total Choroidal Volume in the MRS Group

In MRS eyes, Spearman correlation analysis showed that axial length had a significant negative correlation with the total CV (correlation coefficient $=-0.54088, P=0.0096)$, while age, refractive error, and total RV $\left(12.50 \pm 2.75 \mathrm{~mm}^{3}\right)$ were not $(P=0.7290,0.1476$, and 0.0704 , respectively). On multivariate regression analysis, axial length was the only factor associated with the total CV $(P=0.0459)$; the total $C V$ decreased by $0.19 \mathrm{~mm}^{3}$ per millimeter of axial length. By contrast, age, sex, IOP, refractive error, the presence of posterior staphyloma, partial PVD, epirmacular membrane, type of myopic maculopathy, the presence of EZ defects, retinoschisis subgroup and the total RV were not found to have a significant correlation with the total $\mathrm{CV}(P=0.5900,0.5676,0.6790,0.4990,0.7724,0.1781,0.3087,0.1890,0.8576$, 0.1917 and 0.2688 , respectively) (Table 3 ). 
Table 3

Multivariate Regression Analysis of Factors Affecting Total Choroidal Volume $\left(\mathrm{mm}^{3}\right)$ of MRS

\begin{tabular}{|lll|}
\hline & Parameter estimate & $P$ \\
\hline Intercept & 7.92227 & 0.0060 \\
\hline Age(years) & 0.00653 & 0.5900 \\
\hline Sex & 0.13176 & 0.5676 \\
\hline IOP (mmHg) & -0.02413 & 0.6790 \\
\hline Refractive error (D \pm SD) & -0.01702 & 0.4990 \\
\hline Axial length (mm) & -0.18843 & 0.0459 \\
\hline Posterior staphyloma & -0.07950 & 0.7724 \\
\hline Partial PVD & -0.42914 & 0.1781 \\
\hline Epirmacular membrane & -0.27290 & 0.3087 \\
\hline Type of myopic maculopathy & -0.31988 & 0.1890 \\
\hline Defect of EZ & 0.05324 & 0.8576 \\
\hline Retinochisis Subgroup & -0.37419 & 0.1917 \\
\hline RV(Total,mm ${ }^{3}$ ) & -0.05353 & 0.2688 \\
\hline IOP intraocular pressure; $D$ diopter; $S D$ standard deviation; $P V D$ posterior vitreous detachment; $E Z$ \\
\hline ellipsoid zone; $R V$ retinal volume & & \\
\hline
\end{tabular}

\section{Factors Associated with BCVA and the Integrity of the Ellipsoid Zone in the MRS Group}

In MRS eyes, refractive error was inversely correlated with BCVA (correlation coefficient $=-0.44525, P=$ 0.0107 ) by Spearman correlation analysis, while age, axial length, subfoveal RV and subfoveal CV showed no significant association with BCVA $(P=0.8047,0.2782,0.1168$, and 0.7454 , respectively). In the subsequent multivariate regression analysis, refractive error and the presence of defects in EZ were correlated with BCVA ( $P=0.0075$ and 0.0002 , respectively) and the BCVA decreased by 0.027 logMAR units for each diopter of myopia, while age, sex, axial length, the presence of posterior staphyloma, partial PVD, epimacular membrane, the type of myopic maculopathy, retinoschisis subgroup, the subfoveal RV and the subfoveal CV had no significant association with BCVA $(P=0.5302,0.5705,0.5227,0.6917$, $0.7890,0.3190,0.2023,0.4140,0.2240$ and 0.8644 , respectively) (Table 4). MRS eyes with EZ defects had a significantly greater total RV than MRS eyes with an intact or partially continuous EZ $(P=0.0460)$. There were no significant differences in age, refractive error, axial length, the presence of posterior staphyloma, partial PVD, epimacular membrane, retinoschisis subgroup, subfoveal RV, total CV, or subfoveal CV between MRS eyes with intact or partially continuous EZs and MRS eyes with defective EZs 
$(P=0.0901,0.3494,0.6322,0.7321,0.5687,0.1317,0.1512,0.0641,0.2271$, and 0.4482 , respectively $)$ (Table 5).

Table 4

Multivariate Regression Analysis of Factors Affecting BCVA of MRS

\begin{tabular}{|lll|}
\hline & Parameter estimate & $P$ \\
\hline Intercept & 1.20143 & 0.1756 \\
\hline Age(years) & 0.00247 & 0.5302 \\
\hline Sex & -0.05165 & 0.5705 \\
\hline Refractive error (D \pm SD) & -0.02668 & 0.0075 \\
\hline Axial length (mm) & -0.01969 & 0.5227 \\
\hline Posterior staphyloma & -0.03545 & 0.6917 \\
\hline Partial PVD & -0.02582 & 0.7890 \\
\hline Epimacular membrane & 0.08892 & 0.3190 \\
\hline Type of myopic maculopathy & -0.10234 & 0.2023 \\
\hline Defect of EZ & -0.39674 & 0.0002 \\
\hline Retinochisis subgroup & -0.07383 & 0.4140 \\
\hline RV(Sufoveal,mm ${ }^{3}$ ) & -0.53715 & 0.2240 \\
\hline CV(Sufoveal,mm ${ }^{3}$ ) & -0.37070 & 0.8644 \\
\hline $\begin{array}{l}\text { D diopter; SD standard deviation; } P V D \text { posterior vitreous detachment; EZ ellipsoid zone; } \\
\text { volume; } C V \text { retinal }\end{array}$ & \\
\hline
\end{tabular}


Table 5

Association Between Clinical Characteristics and Integrity of the Ellipsoid Zone of MRS

\begin{tabular}{|c|c|c|c|}
\hline Factor & $\begin{array}{l}\text { Intact or partially continuous in EZ } \\
(n=25)\end{array}$ & $\begin{array}{l}\text { Defect in EZ } \\
(n=7)\end{array}$ & $P$ \\
\hline Age(years) & $61.8 \pm 9.18$ & $66.3 \pm 11.6$ & 0.0901 \\
\hline Refractive error ( $\pm \pm S D)$ & $-12.03 \pm 4.58$ & $-15.0 \pm 7.4$ & 0.3494 \\
\hline Axial length (mm) & $29.3 \pm 1.44$ & $29.9 \pm 1.84$ & 0.6322 \\
\hline Posterior staphyloma (n) & & & 0.7321 \\
\hline present & 20 & 6 & \\
\hline absent & 5 & 1 & \\
\hline \multicolumn{4}{|l|}{ Partial PVD (n) } \\
\hline present & 6 & 1 & 0.5687 \\
\hline absent & 19 & 6 & \\
\hline Epiretinal membrane (n) & & & 0.1317 \\
\hline present & 10 & 5 & \\
\hline absent & 15 & 2 & \\
\hline Retinochisis subgroup (n) & & & 0.1512 \\
\hline outer & 11 & 1 & \\
\hline outer + inner & 14 & 6 & \\
\hline $\mathrm{RV}\left(\right.$ total, $\left.\mathrm{mm}^{3}\right)$ & $11.8 \pm 2.40$ & $14.9 \pm 2.67$ & 0.0460 \\
\hline $\mathrm{RV}$ (subfoveal,mm³) & $0.32 \pm 0.08$ & $0.41 \pm 0.12$ & 0.0641 \\
\hline $\mathrm{CV}\left(\right.$ total, $\left.\mathrm{mm}^{3}\right)$ & $1.36 \pm 0.61$ & $1.08 \pm 0.39$ & 0.2271 \\
\hline CV(subfoveal, $\mathrm{mm}^{3}$ ) & $0.04 \pm 0.02$ & $0.04 \pm 0.01$ & 0.4482 \\
\hline
\end{tabular}

\section{Discussion}

The measurement of the CV in MRS can help evaluate the overall changes in the choroid. Our results showed that the entire macula-involving MRS eyes group had much lower CVs than the emmetropic eyes group and presented significantly lower CVs in the entire macula and EDTRS subfields than the non-MRS highly myopic eyes group. There was no difference in the distribution of the CV in the four quadrants. 
Axial length was the most important factor affecting the total CV in MRS eyes, myopic refractive error and integrity of the EZ were predictive of visual acuity, and defects in the EZ were associated with a greater total macular RV.

It is well recognized that highly myopic eyes have a thin choroid, and the presence of myopic traction maculopathy is related to subfoveal choroidal thinning ${ }^{[22,28-30]}$. In the present study, when compared with emmetropic eyes, highly myopic eyes, including MRS and non-MRS eyes, exhibited much lower macular CVs in the entire macula and all ETDRS subfields. In the research of Barteselli et al [25], the macular total CV in 21 eyes with myopic traction maculopathy (including 3 foveoschisis eyes) was lower than that in 36 highly myopic eyes without choroidoretinal pathology, which may be related to the difference in the average axial length $(28.4 \mathrm{~mm}$ vs $27.6 \mathrm{~mm})$ and the different prevalence of posterior staphyloma ( $16 / 21$ eyes vs $9 / 36$ eyes) between the two groups. In our study, MRS eyes had a lower macular CV than non-MRS highly myopic eyes, probably mainly due to the more serious degree of macular maculopathy in MRS eyes than in non-MRS eyes, even if no difference was found in axial length or the presence of posterior staphyloma between the two groups. Previous reports have indicated that in high myopia, the nasal quadrant is the thinnest region in the macula as measured with the ETDRS grid method, regardless of choroidal thickness or volume ${ }^{[19,22,25,31]}$. We found that there was no significant difference in CV among the superior, inferior, temporal and nasal locations in MRS eyes, although the nasal CV presented the lowest value, which may be related to our exclusion of patients whose PDCA was localized to within an area with a $6 \mathrm{~mm}$ diameter centered on the fovea in our study. As the CV in the PDCA region is close to zero, manual measurements can easily cause errors in these cases.

In the current study, multivariate regression analysis indicated that the total macular $\mathrm{CV}$ was most strongly associated with axial length and not related to the total RV. Previous studies have confirmed that the choroidal thickness in foveal and parafoveal regions decreases with increasing axial length in high myopia ${ }^{[22,25]}$ and calculated that the subfoveal choroid thickness decreases between $19.63 \mu \mathrm{m}$ and 32 $\mu \mathrm{m}$ for every millimeter increase in axial length in adults older than 60 years ${ }^{[17,32]}$. Barteselli et al ${ }^{[25]}$ found that the total macular CV decreased $0.32 \mathrm{~mm}^{3}$ for every millimeter of axial length in highly myopic eyes, including those with MRS, choroidal neovascularization and no choroidoretinal lesions. Choroidal growth is restrained by axial growth of the eyeball during the development of myopia ${ }^{[33]}$, and continuous axial-related choroidal thinning is observed in every stage of myopic maculopathy ${ }^{[22]}$. Eyeball elongation was found to be an important predictor of total choroidal volume alterations in high myopia and was simultaneously considered the initial tractional factor in the occurrence and development of MRS [34]. Whereas, the changes in the choroid appeared to be inconsistent with severity of MRS, as shown in the measurement of RV, we presume that different types and degrees of posterior staphyloma may lead to markedly unbalanced or disproportionate choroidal thinning; furthermore, the pathogenesis of MRS could possibly be attributed to a more complicated mechanism, such as the inward force generated by the asymmetrical progression of posterior vitreous detachment and its different adhesive sites on the retina ${ }^{[14]}$, in addition to the outward force imposing on the retina and choroid. 
In this study, factors such as myopic refractive error and defects in the EZ were determinants of logMAR BCVA in MRS eyes; the BCVA decreased by 0.027 logMAR units for each diopter of myopia, and a greater RV was found in MRS eyes with EZ defects on further analysis. However, the subfoveal CV was not responsible for logMAR BCVA or the integrity of the EZ. Recent studies have investigated the factors affecting the visual acuity of high myopia and found that subfoveal choroidal thickness was an important predictor of BCVA in middle-age and elderly adult high myopia without macular chorioretinopathy ${ }^{[19-21]}$, suggesting that structural alterations in the choroid in high myopia may reflect the inability of the choroid to supply oxygen and nutrients to photoreceptors of the outer retina, which may lead to damage to the photoreceptors and consequent visual dysfunction. However, other findings suggest that the subfoveal choroidal thickness alone is not a sensitive indicator of visual acuity in pathological myopia except at the choroidal neovascularization stage ${ }^{[22,31]}$. Disruption of the EZ on OCT images has been regarded as a sign of damage to the photoreceptors. Ye et al found that the choroid affects visual vision through its interaction with the complex of the myoid zone and the EZ in pathological myopia ${ }^{[35]}$. Cheng et al demonstrated that the severity of the schisic cavity affected the integrity of the EZ and visual prognosis. In their study, eyes with MRS involving the entire macula had a significantly higher prevalence of EZ defects (50\%, $13 / 26$ eyes) and a worse mean logMAR BCVA (0.45) than eyes with less extensive MRS ${ }^{[16]}$. We speculate that mechanical forces resulting in morphological destruction of the retina, including schisic enlargements other than the reduced CV, probably played a more important role in the disruption and even loss of the EZ and the subsequent visual deterioration. There are at least three possible explanations for the insensitivity of the subfoveal $\mathrm{CV}$ in predicting visual acuity in our study. First, $96.9 \%$ (31/32 eyes) of MRS had pathological myopia, which made the subfoveal CV unpredictable for BCVA. Second, the variable choroidal thinning may insufficiently reflect the blood supply of the choroid to the outer layer of the retina compared with the changes in choroidal vascular flow. Third, choroidal thinning or decreased choroidal blood perfusion is an adaptive process resulting from damage to the photoreceptors due to mechanical stress and the reduced nutrition requirement of the photoreceptors from the choroid in MRS.

There are some limitations in our study. First, we did not examine the type of posterior staphyloma in the MRS eyes due to the limited scanning range of the conventional SD-OCT device, as posterior staphyloma plays a key role in the development of MRS ${ }^{[12]}$ and may affect the determination of the ETDRS grids in the macula, which can cause the included RV and CV to be larger than the actual values. Second, due to the lack of built-in software for automatic measurement, the CV had to be manually measured, which inevitably produced measurement errors, especially in MRS eyes with a steep curvature of posterior staphyloma.

\section{Conclusions}

The macular CV was reduced in MRS eyes relative to non-MRS eyes in all regions, and the CV in the nasal region of the macula did not differ from that in the other quadrants. The decreased total macular CV in MRS was associated with axial length, a more myopic status and defects in the EZ played vital roles in 
visual loss. The photoreceptor dysfunction may be mainly brought by mechanical traction exerted on the retina, and the variations in the macular choroid alone insufficiently indicated photoreceptor dysfunction and visual disturbance. Therefore, in MRS, clinicians should pay particular attention to the damage caused by mechanical factors and take measures to postpone this damage, and future studies should focus on changes in choroidal vascular structures and their impact on visual acuity.

\section{Abbreviations}

MRS

Myopic retinoschisis

EZ

Ellipsoid zone

EDI

enhanced depth imaging

SD-OCT

Spectral domain optical coherence tomography

CV

Choroidal volume

BCVA

Best corrected visual acuity

Log MAR

Logarithmic minimal angle of resolution

ETDRS

Early Treatment Diabetic Retinopathy Study

RV

Retinal volume

RPE

Retinal pigment epithelium

PVD

Posterior vitreous detachment

SD

standard deviation

\section{Declarations}

\section{Ethics approval and consent to participate}

The study was following the guidelines of the Helsinki Declaration and was approved by the Ethics Committee of Sixth People's Hospital Affiliated to Shanghai Jiao Tong University, Shanghai, China (Approval NO.: 2020-073). The study was registered in the Chinese clinical trial registry 
(http://www.chictr.org.cn/, Registration number: ChiCTR2000038824). All patients had signed written informed consent for participation.

\section{Consent for publication}

All presentations of the cases have consent for publication.

\section{Availability of data and materials}

The data used and analyzed during the current study are available from the corresponding author on reasonable request. The data supporting our findings can also be found in the Chinese clinical trial registry (http://www.chictr.org.cn/, Registration number: ChiCTR2000038824).

\section{Competing interests}

The authors declare that they have no competing interests.

\section{Funding}

General Program of National Natural Science Foundation of China (81770940).

\section{Authors' contributions}

LS and WQ were responsible for conceiving and designing the study. LS, LT and HJ performed the experiments. LS, LB, CY and ZX collected and analyzed the data. LS wrote the draft. LS and WQ discussed the results and WQ critically reviewed the manuscript. All authors read and approved the final manuscript.

\section{Acknowledgements}

Not applicable.

\section{Authors' information}

1Department of Ophthalmology, Shanghai Jiaotong University Affiliated Sixth People's Hospital, 600 Yishan Road, Shanghai 200233, China.

\section{References}

1. Ruiz-Medrano J, Montero JA, Flores-Moreno I, García-Layana A \& Ruiz-Moreno JM. Myopic maculopathy: Current status and proposal for a new classification and grading system (ATN). Prog Retin Eye Res. 2019 Mar; 69:80-115.

2. Morgan IG, He M, Rose KA. Epidemic of pathologic myopia: what can laboratory studies and epidemiology tell us? Retina. 2017; 37(5):989-97. 
3. Holden BA, Fricke TR, Wilson DA, Jong M, Naidoo KS, Sankaridurg P, Wong TY, Naduviath TJ, Resnikoff S. Global prevalence of myopia and high myopia and temporal trends from 2000 through 2050. Ophthalmology. 2016;123(5):1036-42.

4. Fricke TR, Jong M, Naidoo KS, Sankaridurg P, Naduvilath TJ, Ho SM, Wong TY, Resnikoff S. Global prevalence of visual impairment associated with myopic macular degeneration and temporal trends from 2000 through 2050: systematic review, meta-analysis and modelling. Br J Ophthalmol.2018; 102(7):855-62.

5. Morgan IG, French AN, Ashby RS, Guo X, Ding X, He M, Rose KA. The epidemics of myopia: A etiology and prevention. Prog Retin Eye Res. 2018 Jan; 62:134-49.

6. Verkicharla PK, Ohno-Matsui K, Saw SM. Current and predicted demographics of high myopia and an update of its associated pathological changes. Ophthalmic Physiol Opt. 2015; 35(5):465-75.

7. Ohno-Matsui K, Lai TY, Lai CC, Cheung CM. Updates of pathologic myopia. Prog Retin Eye Res. 2016 May; $52: 156-87$.

8. Varma R, Kim JS, Burkemper BS, Wen G, Torres M, Hsu C, Choudhury F, Azen SP, McKean-Cowdin. Prevalence and causes of visual impairment and blindness in Chinese American adults: the Chinese American Eye Study. JAMA Ophthalmol. 2016; 134(7):785-93.

9. You QS, Peng XY, Xu L, Chen CX, Wang YX, Jonas JB. Myopic maculopathy imaged by optical coherence tomography: the Beijing Eye Study. Ophthalmology. 2014; 121(1):220-4.

10. Matsumura S, Sabanayagam C, Wong CW, Tan CS, Kuo A, Wong YL, Ohno-Matsui K, Wong TY, Cheng CY, Hoang QV, Saw SM. Characteristics of myopic traction maculopathy in myopic Singaporean adults. Br J Ophthalmol. 2020;105(4): 531-7.

11. Takano M, Kishi S. Foveal retinoschisis and retinal detachment in severely myopic eyes with posterior staphyloma. Am J Ophthalmol.1999; 128(4):472-6.

12. Shinohara K, Tanaka N, Jonas JB, Shimada N, Moriyama M, Yoshida T, Ohno-Matsui K. Ultrawidefield OCT to investigate relationships between myopic macular retinoschisis and posterior staphyloma. Ophthalmology. 2019; 125(10):1575-86.

13. Song M, Shen M, Zhou Y, Zheng K, Zhai Y, Xiao M, Wang X, Wang F, Sun X. Observation of vitreous features using enhanced vitreous imaging optical coherence tomography in highly myopic retinoschisis. Retina.2019; 39(9):1732-41.

14. Takahashi H, Tanaka N, Shinohara K, Yokoi T, Yoshida T Uramoto K, Ohno-Matsui. Ultra-widefield optical coherence tomographic imaging of posterior vitreous in eyes with high myopia. Am J Ophthalmol. 2019 Oct; 206:102-12.

15. Shimada N, Tanaka Y, Tokoro T, Ohno-Matsui K. Natural course of myopic traction maculopathy and factors associated with progression or resolution. Am J Ophthalmol 2013,156(5):948-57.

16. Cheng C, Teo K, Tan CS, Lee SY, Loh BK, Wong E, Wong D, Wong TY, Cheung CM. Myopic retinoschisis in asians: structural features and determinants of visual acuity and prognostic factors for progression. Retina. 2016; 36(4):717-26. 
17. Gupta P, Jing T, Marziliano P, Cheung CY, Baskaran M, Lamoureux EL, Wong TY, Cheung CM, Cheng CY. Distribution and determinants of choroidal thickness and volume using automated segmentation software in a population-based study. Am J Ophthalmol.2015;159(2):293-301.

18. Xiang F, He M, Morgan IG. Annual changes in refractive errors and ocular components before and after the onset of myopia in Chinese children. Ophthalmology.2012;119(7):1478-84.

19. Ho M, Liu DT, Chan VC, Lam DS. Choroidal thickness measurement in myopic eyes by enhanced depth optical coherence tomography. Ophthalmology. 2013;120(9):1909-14.

20. Nishida Y, Fujiwara T, Imamura Y, Lima LH, Kurosaka D, Spaide RF. Choroidal thickness and visual acuity in highly myopic eyes. Retina.2012;32(7):1229-36.

21. Flores-Moreno I, Ruiz-Medrano J, Duker JS, Ruiz-Moreno JM. The relationship between retinal and choroidal thickness and visual acuity in highly myopic eyes. Br J Ophthalmol. 2013;97(8):1010-3.

22. Fang Y, Du R, Nagaoka N, Yokoi T, Shinohara K, Xu X, Takahashi H, Onishi Y, Yoshida T, Ohno-Matsui K. OCT-Based Diagnostic Criteria for Different Stages of Myopic Maculopathy. Ophthalmology. 2019;126(7):1018-32.

23. Chhablani J, Barteselli G, Wang H, El-Emam S, Kozak I, Doede AL, Bartsch DU, Cheng L, Freeman WR. Repeatability and reproducibility of manual choroidal volume measurements using enhanced depth imaging optical coherence tomography. Invest Ophthalmol Vis Sci. 2012;53(4):2274-80.

24. Chhablani J, Barteselli G, Bartsch DU, Kozak I, Wang H, El-Emam S,Doede A, Cheng L, Freeman WR. Influence of scanning density on macular choroidal volume measurement using spectral-domain optical coherence tomography. Graefes Arch Clin Exp Ophthalmol. 2013; 251(5):1303-9.

25. Barteselli G, Lee SN, El-Emam S, Hou H, Ma F, Chhablani J, Conner L, Cheng L, Bartsch DU, Freeman WR. Macular choroidal volume variations in highly myopic eyes with myopic traction maculopathy and choroidal neovascularization. Retina. 2014;34(5): 880-9.

26. Ohno-Matsui K, Kawasaki R, Jonas JB, Cheung CM, Saw SM, Verhoeven VJ, Klaver CC, Moriyama M, et al. International photographic classification and grading system for myopic maculopathy. Am $\mathrm{J}$ Ophthalmol.2015;159(5):877-83.

27. Tan CS, Ouyang Y, Ruiz H, dda SR. Diurnal variation of choroidal thickness in normal, healthy subjects measured byspectral domain optical coherence tomography. Invest Ophthalmol Vis Sci.2012; 53(1):261-66.

28. Gupta P, Saw SM, Cheung CY, Girard MJA, Mari JM, Bhargava M, Tan C, Tan M, et al. Choroidal thickness and high myopia: a case-control study of young Chinese men in Singapore. Acta Ophthalmol. 2015; 93(7): e585-92.

29. Pang CE, Sarraf D, Freund KB. Extreme choroidal thinning in high myopia. Retina. 2015;35(3):40715.

30. Abdolrahimzadeh S, Parisi F, Plateroti AM, Evangelista F, Fenicia V, Scuderi G,Recupero MS. Visual acuity, and macular and peripapillary thickness in high myopia. Curr Eye Res.2017;42(11):1468-73.

31. Gupta P, Cheung CY, Saw SM, Koh V, Tan M,Yang A, Zhao P, Cheung CM, et al. Choroidal thickness does not predict visual acuity in young high myopes. Acta Ophthalmol.2017;94(8): e709-15. 
32. Wei WB, Xu L, Jonas JB, Shao L, Du KF, Wang S, Xi C, Xu J, et al. Subfoveal choroidal thickness: the Beijing Eye Study. Ophthalmology. 2013;120(1):175-80.

33. Xiong S, He X, Zhang B, Deng J, Wang J, Lv M, Zhu J, Zou H, Xu X. Changes in Choroidal Thickness Varied by Age and Refraction in Children and Adolescents: A 1-Year Longitudinal Study. Am J Ophthalmol. 2020 May; 213:46-56.

34. Gohil R, Sivaprasad S, Han LT, Mathew R, Kiousis G, Yang Y. Myopic foveoschisis: a clinical review. Eye (Lond). 2015;29(5):593-601.

35. Ye J, Shen M, Huang S, Fan Y, Yao A, Pan C, Shi X, Lu F, Shao Y. Visual Acuity in Pathological Myopia Is Correlated With the Photoreceptor Myoid and Ellipsoid Zone Thickness and Affected by Choroid Thickness. Invest Ophthalmol Vis Sci. 2019;60(5):1714-23.

\section{Figures}
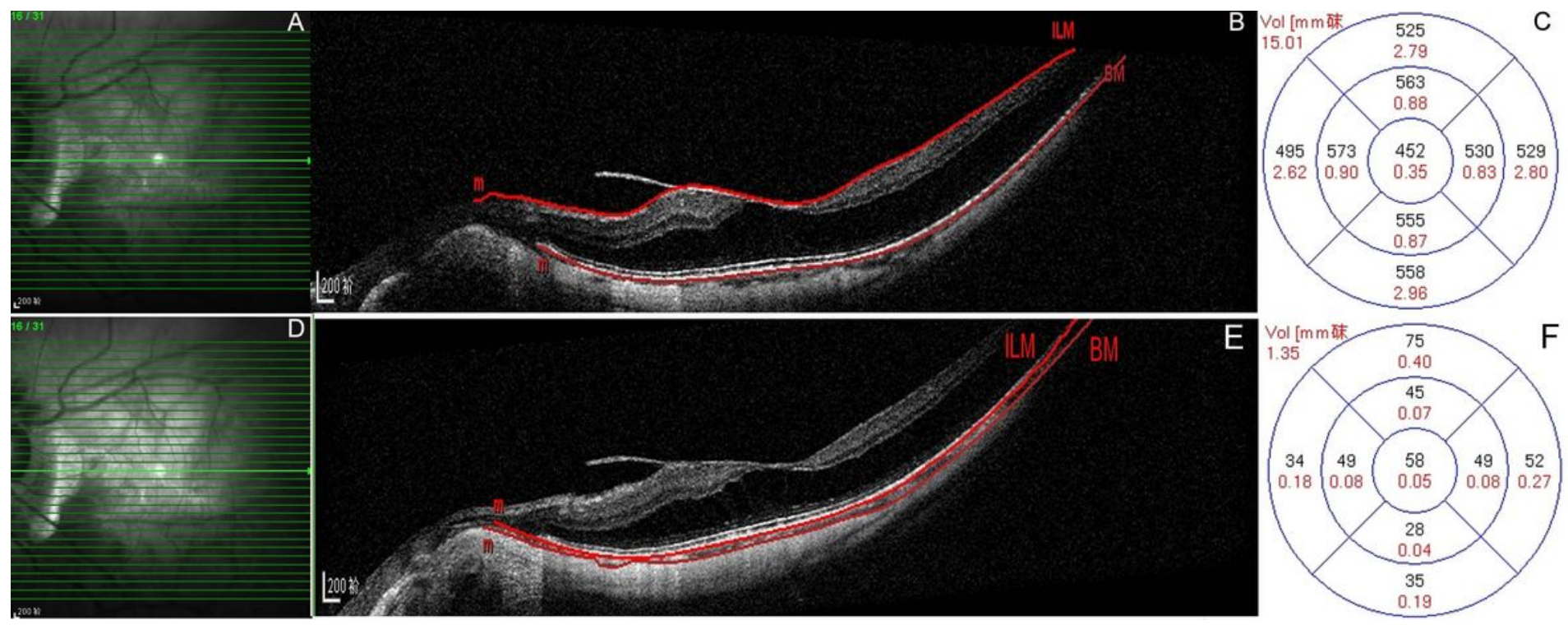

\section{Figure 1}

Measurement mode of retinal and choroidal volume. SD-OCT B-scan protocol from routine mode in the horizontal direction (a). Automated segmentation for retinal volume (b). Measurements of retinal volume on the ETDRS grid (c). SD-OCT B-scan protocol from enhanced depth imaging mode in the horizontal direction (d). Manual segmentation for choroidal volume (e). Measurements of choroidal volume on the ETDRS grid (f). 

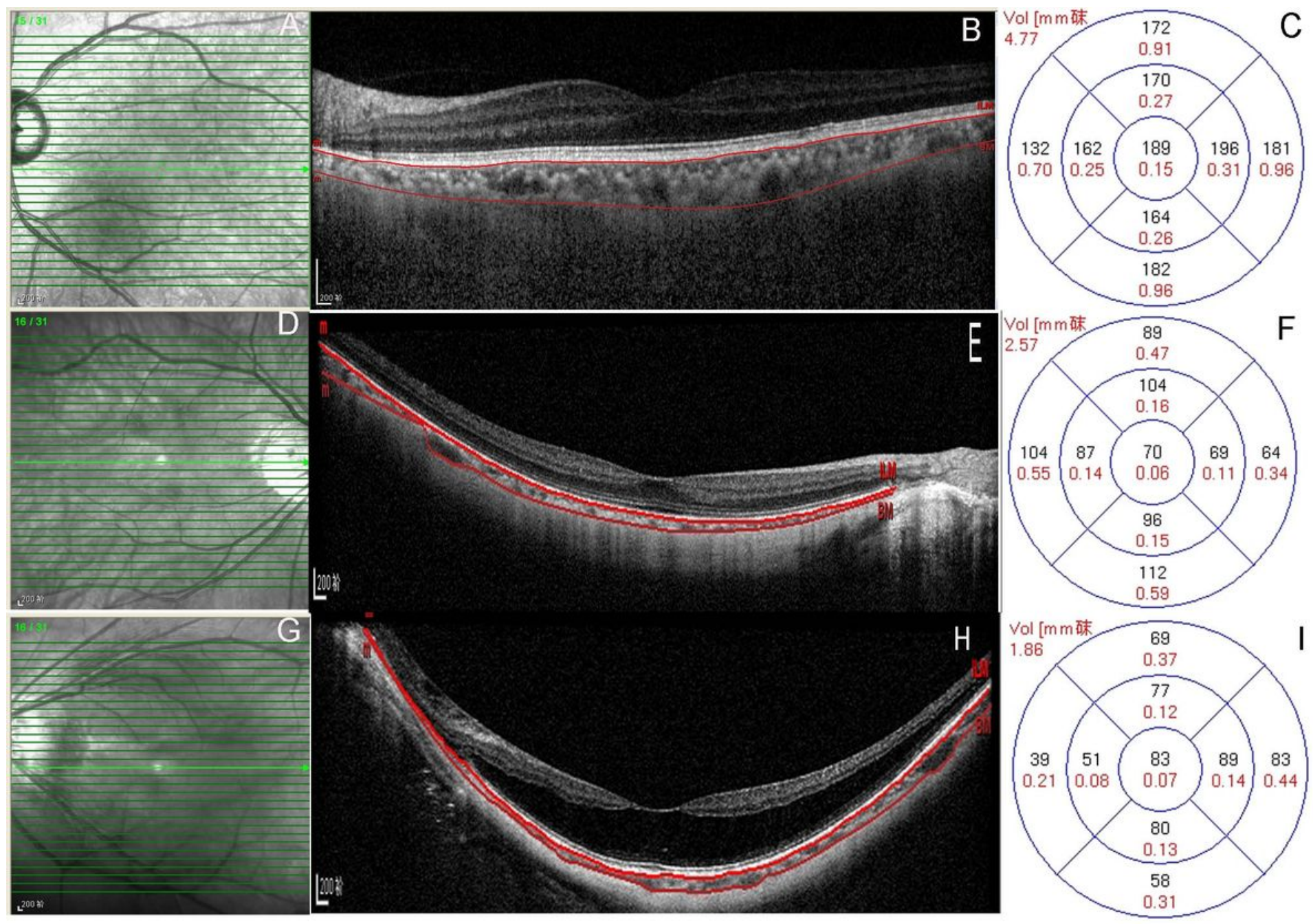

Figure 2

SD-OCT B-scans from enhanced depth imaging mode, images through the fovea and maps of the choroidal volume (CV) in the ETDRS grids. The emmetropic eye has a total macular CV of $4.77 \mathrm{~mm} 3$ and a subfoveal CV of $0.15 \mathrm{~mm} 3$ with an axial length of $23.98 \mathrm{~mm}(a, b, c)$. The non - MRS highly myopic eye has a total macular CV of $2.57 \mathrm{~mm} 3$ and a subfoveal CV of $0.06 \mathrm{~mm} 3$ with an axial length of $27.46 \mathrm{~mm}$ (d, e, f). g-i. The MRS eye has a total macular CV of $1.86 \mathrm{~mm} 3$ and a subfoveal CV of $0.07 \mathrm{~mm} 3$ with an axial length of $29.40 \mathrm{~mm}(\mathrm{~g}, \mathrm{~h}, \mathrm{i})$. 